\title{
Surface features on Sahara soil dust particles made visible by atomic force microscope (AFM) phase images
}

\author{
G. Helas and M. O. Andreae \\ Max Planck Institute for Chemistry, Biogeochemistry Department, P.O.Box 3060, 5020 Mainz, Germany
}

Received: 23 July 2008 - Published in Atmos. Meas. Tech. Discuss.: 20 August 2008

Revised: 22 October 2008 - Accepted: 22 October 2008 - Published: 29 October 2008

\begin{abstract}
We show that atomic force microscopy (AFM) phase images can reveal surface features of soil dust particles, which are not evident using other microscopic methods. The non-contact AFM method is able to resolve topographical structures in the nanometer range as well as to uncover repulsive atomic forces and attractive van der Waals' forces, and thus gives insight to surface properties. Though the method does not allow quantitative assignment in terms of chemical compound description, it clearly shows deposits of distinguishable material on the surface. We apply this technique to dust aerosol particles from the Sahara collected over the Atlantic Ocean and describe micro-features on the surfaces of such particles.
\end{abstract}

\section{Introduction}

Empirical investigation of the micro-cosmos surrounding us started with the advent of the optical microscope. Using light rays for rendering images, microscopes historically were limited by diffraction, leading to resolutions close to a micrometer. Modern developments have improved the lateral resolution, among others, by making use of interatomic forces for rendering; this technique is named atomic force microscopy (AFM).

In AFM (Bonnell, 2001), a fine tip is used as a probe to scan a surface, and the interaction between the probe and the surface makes it possible to map lateral information if the location of the interaction is determined independently. In its most simple form, called the contact mode, such a tip would touch the surface while moving across. The tip, which is guided mechanically and/or by expansible piezo-crystals, has to follow the terrain, or topography, when led over the

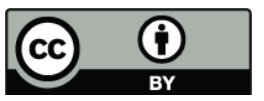

Correspondence to: G. Helas (gth@mpch-mainz.mpg.de) object of interest. So, by rastering with a constant force over the object to be investigated, an image is formed line by line. The forces employed on the surface are bounded by the hardness of the specimen investigated, i.e., by indenting, and the attractive term of the van der Waals' forces between atoms.

This use of van der Waals' forces led to the name of atomic force microscopy (AFM), and this technique is one possibility in what today is designated as scanning probe microscopy (SPM). The use of piezo-crystals leads to the high resolution achievable, which may extend into the range of crystal lattices or even of atoms.

The tips used for scanning commonly are conical or pyramidal in shape, which poses an inherent limitation to this type of microscopy. While force interaction between probe and specimen mainly acts via the ultimate atoms of the tip and the surface layer of the sample, the geometric shape of the tip prevents lateral sensing of vertical surfaces. The topographic structure determined is always a convolution of the shape of the tip and the surface. These characteristics become more pronounced the smaller the features to be investigated are compared to the size of the tip. Although procedures to remove the influences of the tip shape from images are available (Villarubia, 1994), they are to be used with caution.

An improvement over the contact mode, in terms of gentler interaction with the specimen to be investigated, is to apply a vibration orthogonal to the sample and make use of the resonant frequency of the cantilever bearing the tip used for investigation. While hovering above the surface, the tip comes into the range of the basic Fermi repulsion and attractive van der Waals' interaction, so that additional forces act on the vibrating tip and cantilever, and thus shift either the frequency or the phase of its vibration (Giessibl, 1995; Sokolov et al., 1999; García and Pérez, 2002; Morita et al., 2002). Hence the vibrating tip becomes "de-tuned", a value which can be measured very precisely. This method, addressed as non-contact AFM (NC-AFM), has the advantage

Published by Copernicus Publications on behalf of the European Geosciences Union. 
that the tip ideally does not touch the sample to be investigated.

Unfortunately, the increase in sensitivity provided by this method is traded off by the fact that the frequency, or phase shift, is relative and the van der Waals' forces are extremely difficult to quantify directly, as many parameters of the experimental set-up have influence. Within one image, however, when the tip and mounting, basic eigenfrequency etc. remain constant, the shift in frequency or phase is a direct indicator of the van der Waals' force. These forces are traceable to material constants, and can be displayed in addition to the topography of the specimen under investigation.

In a mixed mode, which is designated as intermittentcontact, or tapping, the vibrating cantilever tip is brought closer to the sample and its vibration amplitude is greater, so that at the bottom of its travel it just barely touches the sample surface. Then, however, friction and other lateral forces may become important. Combining this mixed mode with phase information has been widely applied to compliant materials, i.e., synthetics (Viswanathan et al., 1997; Magonov et al., 1997), with water- and organics-coated ammonium sulfate (Dong and Yu, 2003), and in catalysis research (Dokou et al., 2000; Carvalho et al., 2004). To access material properties, Dauphin et al. (2003) specifically used the phase shift signal to investigate aragonitic and calcitic layers in shells.

A further scanning probe method, which is called "electrostatic force microscopy" (EFM) or Kelvin probe microscopy (Martin et al., 1988; Nonnenmacher et al., 1991; Takahashi and Kawamukai, 2000; $\mathrm{Na}$ et al., 2007) is available for addressing the permittivity of the material under investigation. Here, the electrostatic force between the surface charge and a biased, non-contact cantilever is used for mapping. Kelvin Probe microscopy is mainly used in surface investigations of semiconductors.

Aerosol and similar microscopic particles have been investigated with the help of AFM, by, among others, Demanet (1995), Friedbacher et al. (1995), Köllensperger et al. (1997, 1998, 1999), Bosbach and Enders (1998), Pósfai et al. (1998), Lehmpuhl et al. (1999), Ramirez-Aguilar et al. (1999), Barkay et al. (2005), Wittmaack and Strigl (2005), and Gwaze et al. (2007). In the beginning, contact mode was employed, but from 1999 on intermittent contact mode AFM has been used in most cases. Phase shift imaging of hard materials with AFM was used to highlight topographic features. To the best of our knowledge, AFM phase shift information as evidence for different material properties has not been employed in aerosol research.

Several previous investigations have reported coatings on atmospheric desert dust particles. Levin et al. (1996) obtained indirect evidence from the fact that the amount of sulfate found with particles was related to their surface area and not to their volume. Similar arguments have also been used by Falkovich et al. (2001) and Barkay et al. (2005). Trochkine et al. (2003) deduced, from increasing sulfur to silicon ratios in aerosol particles, contributions from the gas phase after transport from China to Japan. Also, Kojima et al. (2006) concluded that there were acquired sulfate coatings on dust particles from their TEM investigations. Under such analytical conditions, however, the particles disintegrate so that the coatings as such do not necessarily become visible. A new approach to deposits on aerosol particles has been tested by Semeniuk et al. (2007). They employed an environmental transmission electron microscope (ETEM) when looking for water uptake by individual atmospheric particles having sulfate and chloride coatings. Unfortunately, the transmission electron microscopic procedures also result in the destruction of the particles.

We applied a non-destructive technique, non-contact AFM, to Sahara dust particles and could show that phase shift information has the potential to reveal the presence of different surface material properties. Used together with height information from the AFM, this made it possible to identify deposits on individual aerosol particles.

\section{Experimental}

We used a C/P-Research AFM from ThermoMicroscopes (now Veeco Instruments, USA) placed on a pneumatic table to reduce interferences from building vibrations. Reflective Tapping Mode Etched Silicon Probes, Symmetric Tip (RTESPA, Model MPP-11120) tips from Veeco were used at frequencies typically close to $400 \mathrm{kHz}$. The microscope was calibrated vertically with standards from MTD Co, Moscow, Russia (TGZ1=19 nm and TGZ2=104 nm) and laterally with an AFM calibration grid from ThermoMicroscopes, Inc., USA (0.9 to $5.2 \mu \mathrm{m})$. Lateral drift was not observed during the experiments and vertical drift remained below 5\%. The AFM was used under ambient conditions. The relative humidity was not controlled but remained close to $40 \%$ throughout the measurements.

The sample of Sahara dust probed was collected on the Atlantic ocean during cruise number M21 of the German research vessel "Meteor" when a strong dust outbreak from the Sahara was encountered on 29 and 30 April 1992 on the N. Atlantic close to $47.2^{\circ} \mathrm{N}, 18.5^{\circ} \mathrm{W}$ (for details, see Andreae et al., 2003).

The aerosol particles were collected on a Nuclepore ${ }^{\circledR}$ polycarbonate filter. A cut-out of approximately $1.5 \times 3 \mathrm{~mm}$ was used. This small strip was glued to a conductive carbon tab which in turn was put on a nickel disc. This disc was mounted on the three-dimensional piezo-scanner. All surfaces shown here pertain to particles larger than $3 \mu \mathrm{m}$ in height, which exceeds the vertical usable range of our AFM scanner. Therefore no full AFM images of the scanned particles were made in order to prevent tip crash. A SEM image of the same filter, though not the same cut-out, is provided in Winterholler et al. (2006).

Images were created with $256 \times 256$ to $1024 \times 1024$ pixels at scan speeds below one second per line. The full scanned 

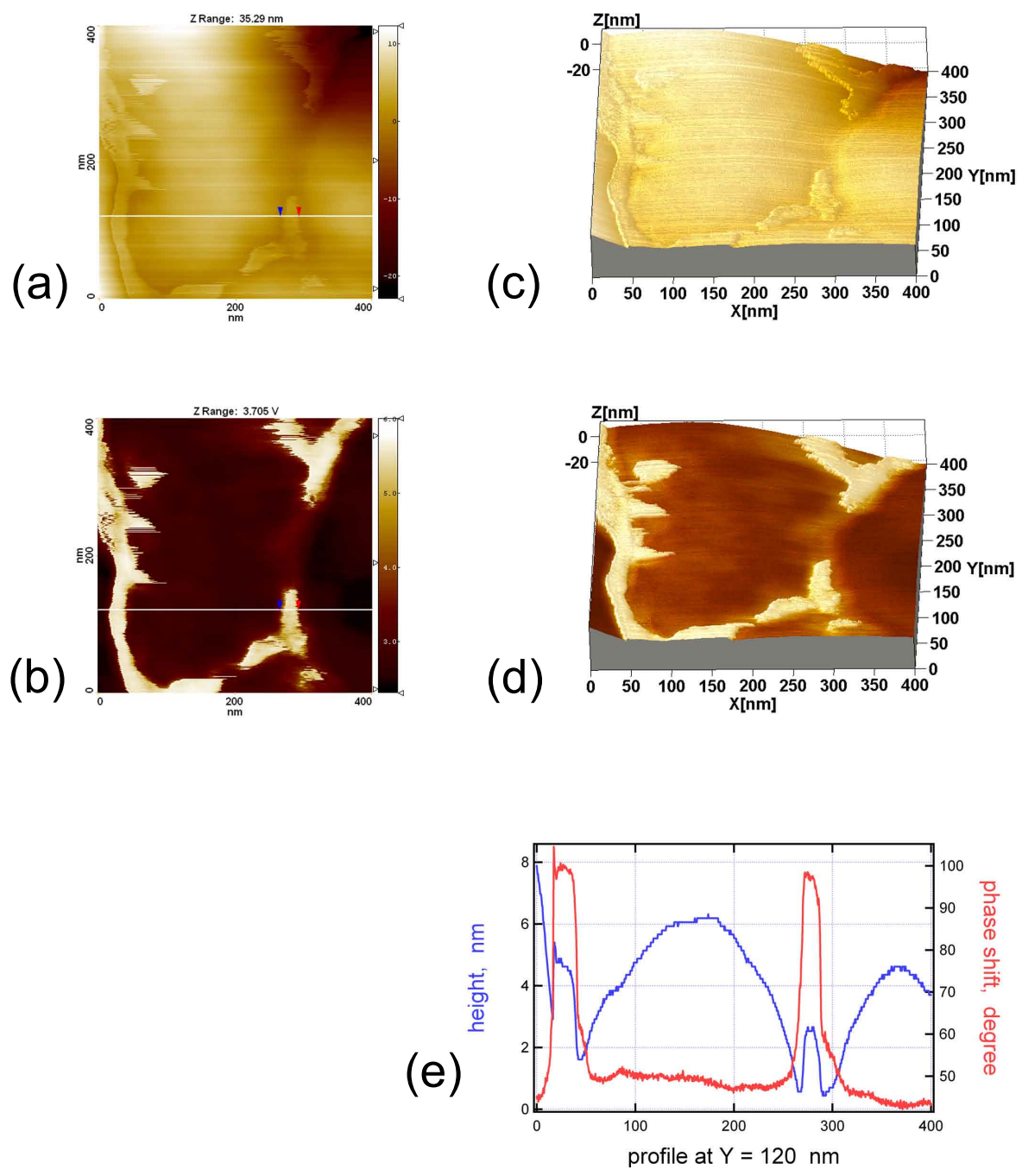

Fig. 1. (a) Topographic image of the surface of part of a Sahara dust particle. Dark parts represent lower areas while bright is associated with higher topographic levels. The white horizontal line marks the cut for the profile given in diagram (e). (b) Phase shift image for the same area as given in (a). Colors represent phase shifts and thus variations point to changes in material properties. (c) A 3-dimensional rendering of the topographic image given in (a). Again dark parts represent lower areas while bright is associated with higher topographic levels. (d) Same 3-dimensional rendering as in (c), however, now the color coding of the phase image is applied. (e) Profile along the white line shown in (a) and (b) presenting the variation in height and phase shift respectively.

area has not been analyzed in all cases. Parallel to height measurements, phase shift signals were acquired and in some cases electrostatic force information as well. In our imaging experiments, the phase signals showed higher sensitivity, therefore they were used primarily.

Images have been processed with the computer program SPIP from Image Metrology A/S, Denmark.

\section{Results}

We show four examples of surface features found on Sahara dust particles. The AFM images show distinguishable material deposited mainly into depressions of larger particles in
Figs. 1, 2 and 3, and an example of an incomplete covering layer in Fig. 4. Topographical AFM images typically are color coded by showing elevated areas in bright, here bright yellow, and lower areas in dark, here dark brown. No smoothing has been applied to the images, and consequently to the profiles.

In Fig. 1a, which covers $400 \times 400 \mathrm{~nm}^{2}$ of the surface of a dust particle, the lowest part can be found in the upper right corner. A U-shaped groove, best visible on the left side and the bottom of the image, appears to be partly filled. The phase image, depicted in Fig. $1 \mathrm{~b}$ recognizes the deposits as being of different material than the substrate. In this figure, the different colors code the measured phase shift of the 

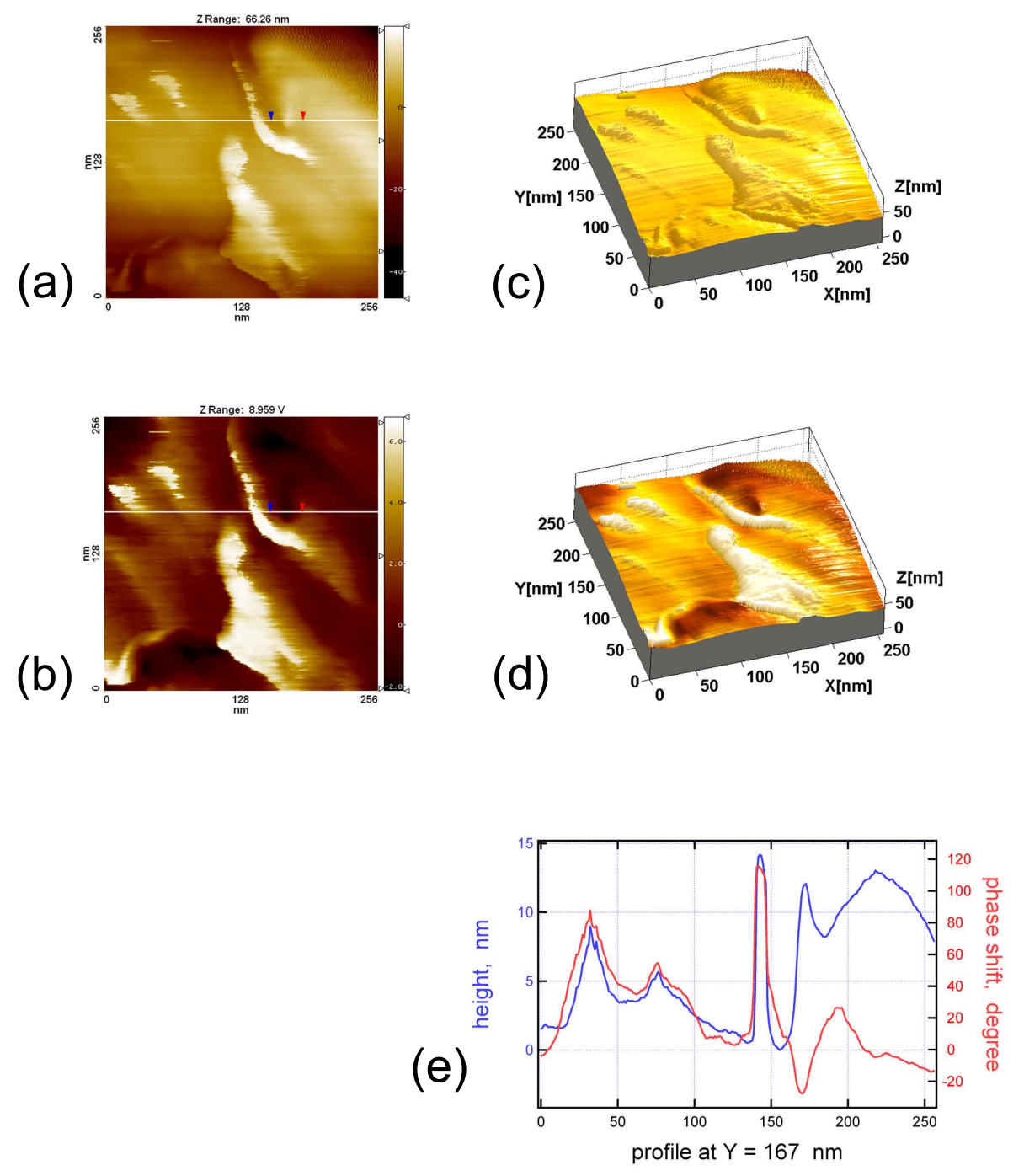

Fig. 2. As in Fig. 1.

oscillating cantilever-tip ensemble. Figure 1c gives a three dimensional impression of the imaged section of the surface, and in Fig. 1d the surface is coded according to the observed phase shift. This shows the fillings to be a feature independent of the substrate. Finally, Fig. 1e presents the height profile along the white bar at $Y=120 \mathrm{~nm}$ given in Fig. 1a and $b$. The phase shift of approximately $45^{\circ}$ occurs exactly over the deposits, which are 2 to $3 \mathrm{~nm}$ higher than the direct surrounding. The substrate itself is in some parts distinctly higher than the fillings, as can be seen from the profile.

The second example demonstrates that the elevations are not necessarily positively correlated with phase shift changes. The image in Fig. 2a covers $256 \times 256 \mathrm{~nm}^{2}$, with a profile at $\mathrm{Y}=167 \mathrm{~nm}$ showing two markers that bracket a ridge measured in the topography. While the terrain rises, the phase signal drops in contrast to the ridge at the left and also to the previous case. The representation and the color coding of the images is the same as in Fig. 1.
A similar setting is seen in Fig. 3a to g. Again, Fig. 3a and $\mathrm{b}$ shows the topographical and phase shift information over an area of $256 \times 256 \mathrm{~nm}^{2}$ of a dust particle. Here, a groove extending from the lower part to the right and then bending off upwards appears to be partly filled, and again the phase shift image reveals these deposits to be of different material than the substrate particle itself. Here additionally, the EFM image is depicted in Fig. 3c, which shows the permittivity of the material probed (in arbitrary units). As did the phase signal, the EFM signal proves the filling to be of a different material than the substrate particle. The filling measured along the white bar of $128 \mathrm{~nm}$ length (Fig. 3b) appears to be of some 3 to $4 \mathrm{~nm}$ in height. Obviously, this is sufficient to make the material properties distinguishable. Again Fig. 3d shows the topography as a 3-dimensional surface, while Fig. 3e and $\mathrm{f}$ represent the surface "skinned" with the phase coding and the relative permittivity signal, respectively. Phase shift and terrain height across the groove appear co-located in the profile 
(a)

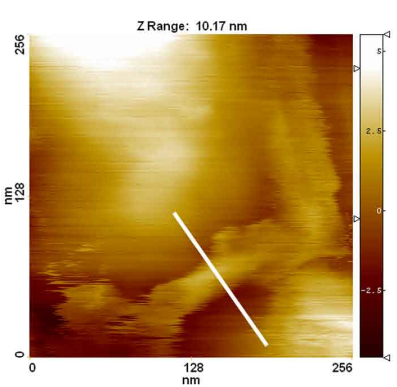

(b)

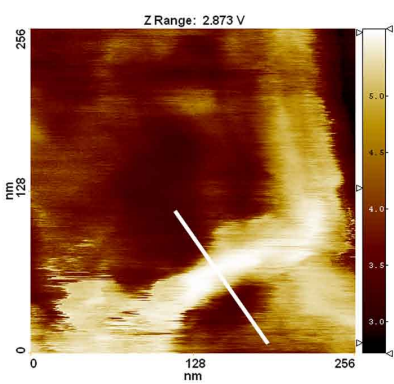

(c)

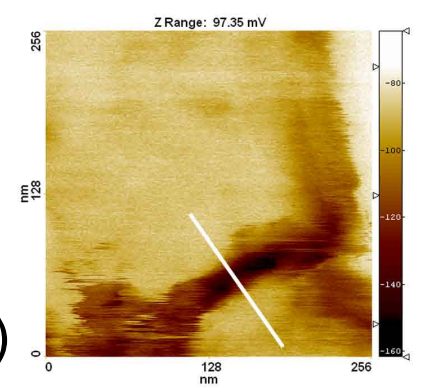

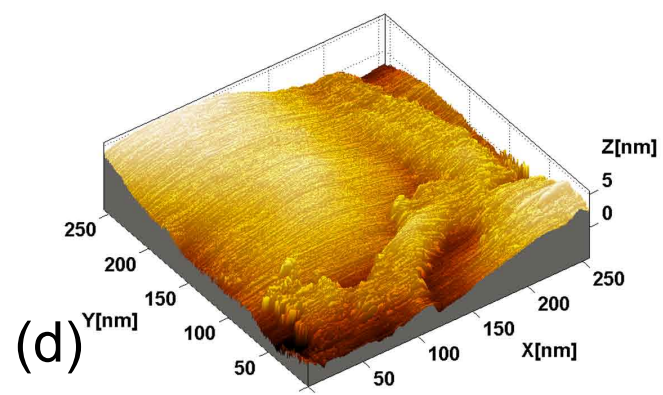

(e)
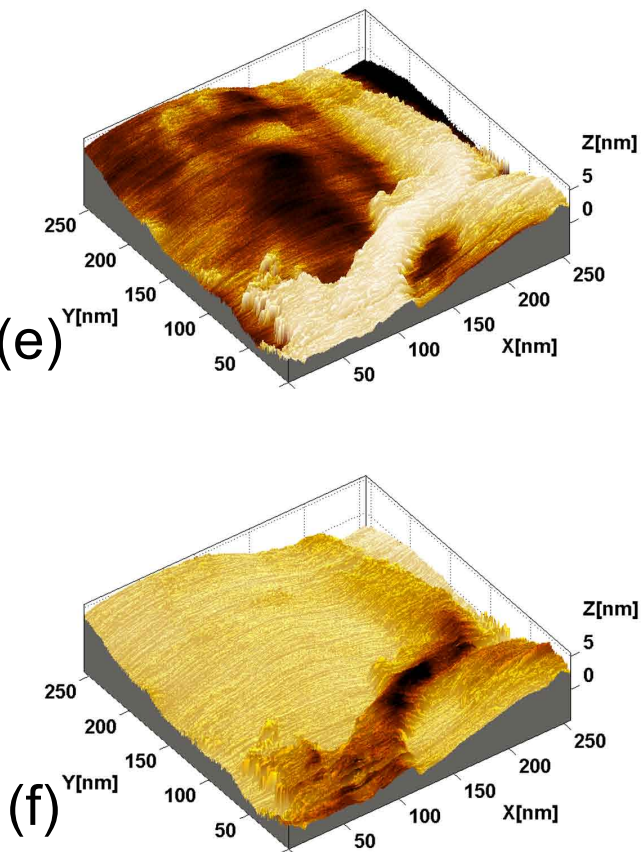

(g)

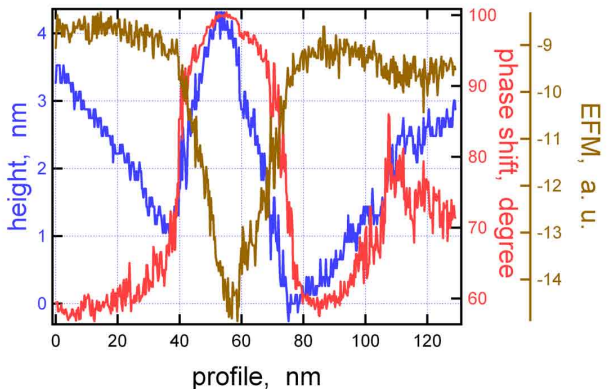

Fig. 3. Information is similar to the other figures, except that the EFM signal has been added (c), and respective 3-dimensional rendering is given in (f). Profile (g) additionally presents the EFM signal.

graph in Fig. 3g as does the permittivity. The EFM signal varies accordingly, but obviously is much less sensitive. The inverted signal is due to the lock-in settings.

Finally, Fig. 4, with similar display as in the previous ones, indicates that larger areas can be coated. Indeed, approxi- mately half the area here of $250 \times 250 \mathrm{~nm}^{2}$ seems to be covered. Topographic features in the openings of the relatively flat terrain are visible. Again the profile at $\mathrm{Y}=60 \mathrm{~nm}$ given in Fig. 4e proves that the edge of the openings coincides with the change in phase signal. 


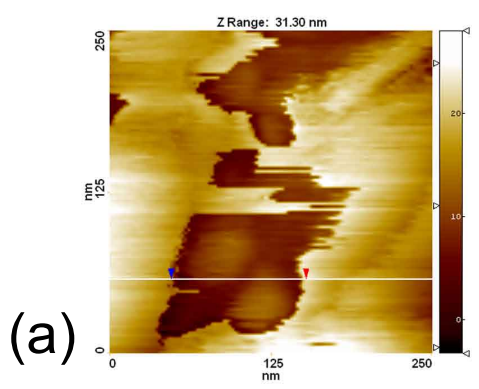

(c)
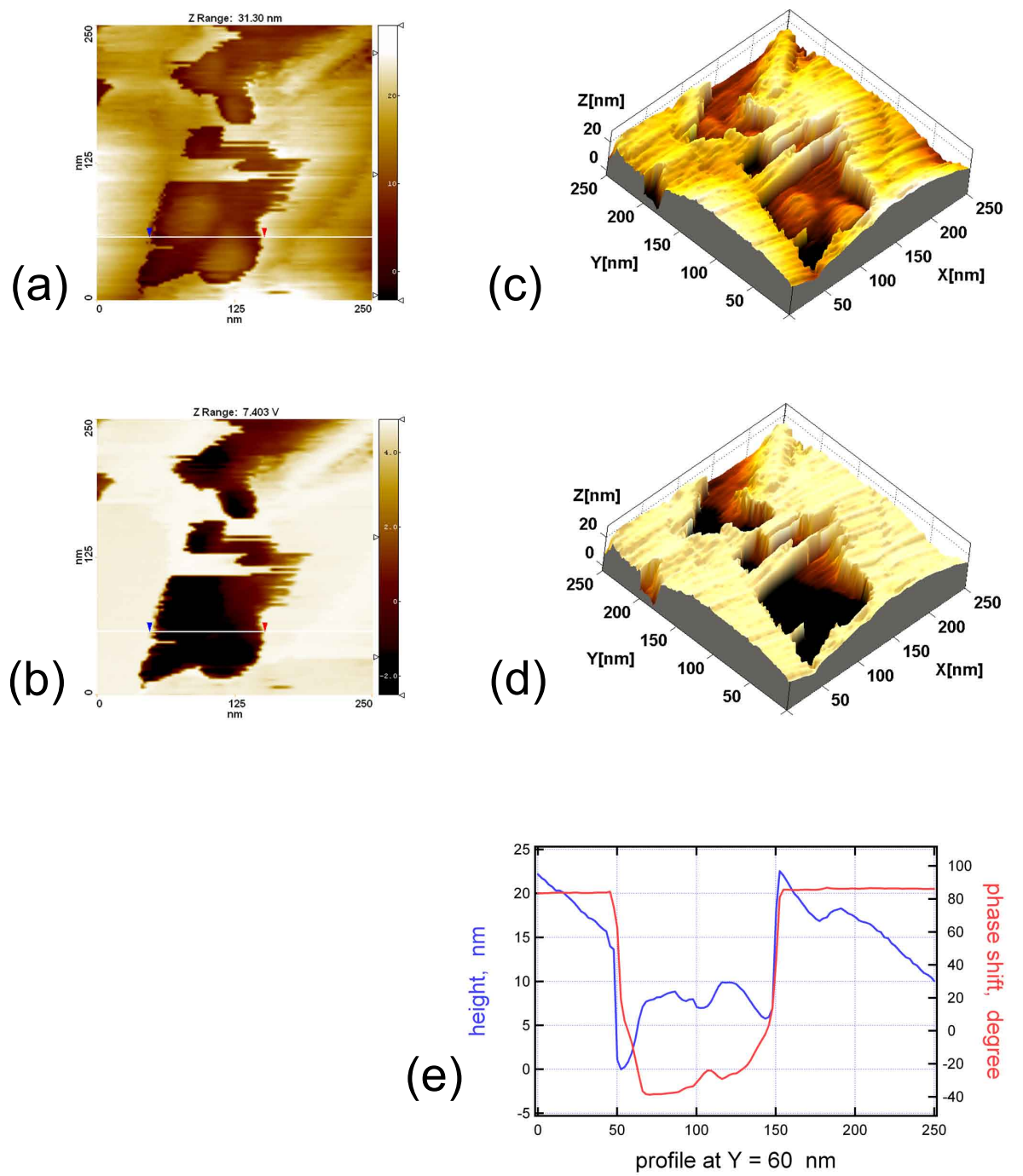

Fig. 4. As in Fig. 1.

\section{Discussion}

The width of the deposits as observed in the topographic and phase shift images in our experiments vary, but are as small as a few tens of nanometers. A lateral resolution between 0.25 and $1 \mathrm{~nm}$ per pixel has been employed in these images, making the observed lateral information significant.

It is of course not possible to derive the thickness of the "add-on" material from the topographical image. Nevertheless, extending the curvatures adjacent to the grooves in Figs. 1 and 2 would suggest a height of a few nanometers, which translates to some ten atomic or molecular layers.

The phase shift signal provided by our method yields information on different material properties. As several experimental parameters influence the values of the phase shift (Brandsch et al., 1997; Kühle et al., 1997; James et al., 2001; García and Perez, 2002), it is not meaningful to rely on the absolute values, which in our experiments ranged from ap- proximately -20 to +120 degrees. The relative shifts reported here, however, clearly exceed the noise range of the measured signals, (our worst case is shown in Fig. 3f). The phase shift value given in one image pixel is obtained from at least 35 vibration cycles, but usually from more than 100 . Color and color depth in the images aid in the visualization of the features. They should not be used alone for assessment, as the color scale always tries to match the full range measured. As with the phase shift values, the EFM results are also relative. We have not yet been able to calibrate them quantitatively.

The AFM tip and mounting remain constant within one image, and thus the eigenfrequencies of the tip-cantilever ensemble are fixed once it is assembled. The free parameters in our AFM are the excitation of vibration of the cantilever and distance between tip and sample, the latter of which is the most critical one. The closer the distance the stronger is 
the phase shift. This is theoretically supported by Sokolov and Henderson (2000). These authors also state that due to the high sensitivity of the tip-sample distance, instabilities and artifacts in the measurements are possible. We deduce from our simultaneously obtained EFM signals that the phase shift information, and thus the change in material properties is real, albeit we have no knowledge of the chemical composition.

Step heights of a few nm clearly are sufficient to be recognized in the topography, which would correspond to some ten atomic or molecular layers. To sense force irregularities leading to phase shifts, four layers would suffice according to Sokolov and Henderson (2000), provided the tip-sample distance is correctly chosen. The ability to distinguish sharply between two different types of material is a hallmark of this method of AFM, and can not be matched by the X-ray investigation applied in scanning electron microscopy, where the electron interaction volume necessary for discrimination is much larger (Goldstein et al., 1992).

Other methods that could be used to investigate such tiny features are electron microscopy, both scanning (SEM) as well as transmission (TEM), secondary ion mass spectrometry (SIMS, nanoSIMS), and laser Raman spectroscopy. SEM certainly is able to resolve features in the size range we are dealing with, as is TEM. TEM additionally has the possibility to identify crystalline structures and elemental composition, but is a destructive method, as is NanoSIMS, which also has much lower resolution. Laser Raman spectrometry has been tested, but failed because the deposits were volatilized in course of the investigations (unpublished results). We thus consider AFM a method that provides unique information and is complementary to other microscopic techniques. It also has the advantage of working in ambient conditions.

The origin and composition of the surface deposits that we observed on the Sahara dust particles cannot be determined with our methods, and there are several possibilities to take into account. As the sample was stored in a sealed container, we assume (but cannot prove) that the deposits on the particles were present before collection and are not due to storage artifacts. The particles may have entered the atmosphere already having the deposits or coating, or may have acquired them by coagulation with other particles during atmospheric transport or cloud processing (Andreae et al., 1986). Finally, reactions, most likely heterogeneous processes, can have occurred on the particles. Such heterogeneous processes could of course also have taken place during cloud processing, if the dust particles were incorporated into large droplets first (Levin et al., 1996). Given the atmospheric residence time of our particles of approximately 10 days (Andreae et al., 2003), it is not unlikely that the deposits were added in transport. The fact that we find the additional material often in grooves on the investigated particles may point to dissolution and precipitation at the micro-scale. "Visual" inspection of such surface features may influence how particle properties are perceived. Though being beyond the range of our present investigation, understanding these processes may have repercussions on our perception of wettability, optical, and related properties of atmospheric particles.

Previous investigations have provided, sometimes indirect, evidence for coatings on atmospheric desert particles (Levin et al., 1996; Falkovich et al., 2001; Trochkine et al., 2003; Barkay et al., 2005; Kojima et al., 2006; Semeniuk et al., 2007). However, the methods used in these studies did not allow the investigation of undisturbed layers at resolutions down to individual or few lattice layers, a requirement when considering the sizes of the aerosols in question.

AFM phase images are unique in that they have the potential to make surface features on aerosol particles visible. In our case, it is tempting to associate the observed "addon" features with sulfate coatings, as we know that individual dust particles from this filter sample contain sulfur (Winterholler et al., 2006). It is regrettable, however, that we don't yet have direct AFM-based evidence enabling us to deduce the chemical composition. Further studies should exploit EFM methods in more detail, and explore spectroscopic techniques that can be combined with AFM.

\section{Conclusions}

We show the presence of surface features on Sahara dust particles, which we can identify as being deposits of different material by means of phase shift atomic force microscopy. Additional support for this assessment is provided by electrostatic force measurements. The chemical composition of the deposits cannot be determined with the methods applied. Nevertheless, the images document very well the deposits and incomplete coating found on the aerosol particles, which in traditional terminology would be called internally mixed particles. Deposits often are found in grooves, but can also cover larger areas. The visualization of the surface features may help to assess their relevance for the properties of aerosols.

Acknowledgements. Edited by: A. Wiedensohler

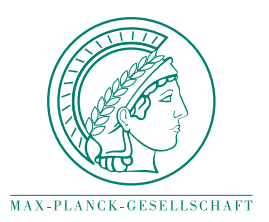

This Open Access Publication is financed by the Max Planck Society.

\section{References}

Andreae, M. O., Charlson, R. J., Bruynseels, F., Storms, H., van Grieken, R. E., and Maenhaut, W.: Internal mixture of sea salt, silicates and excess sulfate in marine aerosols, Science, 232, 1620-1623, 1986.

Andreae, M. O., Andreae, T. W., Meyerdierks, D., and Thiel, C.: Marine sulfur cycling and the atmospheric aerosol over the springtime North Atlantic, Chemosphere, 52, 1321-1343, 2003. 
Barkay, Z., Teller, A., Ganor, E., Levin, Z., and Shapira, Y.: Atomic force and scanning electron microscopy, Microsc. Res. Techniq., 68, 107-114, 2005.

Bonnell, D.: Scanning Probe Microscopy: Theory, Techniques, and Applications, Wiley-VCH, New York, USA, p. 493, 2001.

Bosbach, D. and Enders, M.: Microtopography of high-calcium fly ash particle surfaces, Adv. Cem. Res., 10, 17-23, 1998.

Brandsch, R., Bar, G., and Whangbo, M.-H.: On the factors affecting the contrast of height and phase images in tapping mode atomic force microscopy, Langmuir, 13, 6349-6353, 1997.

Carvalho, M. C. N. A., Perez, C. A., Simão, Passos, F. B., and Schmal, M.: The promoting effect of cesium structure and morphology of silver catalysts, An. Acad. Bras. Ciências 76, 19-27, 2004.

Dokou, E., Stangland, E. E., Andres, R. P., Delgass, W. N., and Barteau, M. A.: Comparison of AFM and HRTEM to determine the metal particle morphology and loading of an $\mathrm{Au} / \mathrm{TiO}_{2}$ catalyst, Catal. Lett., 70, 1-7, 2000.

Dauphin, Y., Guzman, N., Denis, A., Cuif, J.-P., and Ortlieb, L.: Microstructure, nanostructure and composition of the shell of Concholepas concholepas (Gastropoda, Muricidae), Aquat. Living Resour., 16, 95-103, 2003.

Demanet, C. M.: Atomic force microscopy determination of the topography of fly-ash particles, Appl. Surf. Sci., 89, 97-101, 1995.

Falkovich, A. H., Ganor, E., Levin, Z., Formenti, P., and Rudich, Y.: Chemical and mineralogical analysis of individual mineral dust particles, J. Geophys. Res., 106, 18 029-18 036, 2001.

Friedbacher, G., Grasserbauer, M., Mesimani, Y., Klaus, N., and Higatsberger, J.: Investigation of environmental aerosol by atomic force microscopy, Anal. Chem., 67, 1749-1754, 1995.

García, R. and Pérez, R.: Dynamic atomic force microscopy methods, Surf. Sci. Rep., 47, 197-301, 2002.

Giessibl, F. J.: Atomic resolution of the silicon (111)-(7x7) surface by atomic force microscopy, Science, 267, 68-71, 1995.

Goldstein, J. I., Newbury, D. E., Echlin, P., Joy, D. C., Romig Jr., A. D., Lyman, C. E., Fiori, C., and Lifshin, E.: Scanning electron microscopy and X-ray microanalysis, Plenum Press, New York, USA, 1992.

Gwaze, P., Annegarn, H. J., Huth, J., Helas, G.: Comparison of particle sizes with impactor, AFM and SEM, Atmos. Res., 86, 93-104, 2007.

James, P. J., Antognozzi, M., Tamayo, J., McMaster, T. J., Newton, J. M., and Miles, M. J.: Interpretation of contrast in tapping mode AFM and shear force microscopy. A study on Nafion, Langmuir, 17, 349-360, 2001.

Kojima, T., Buseck, P. R., Iwasaka, Y., Matsuki, A., and Trochkine, D.: Sulfate-coated dust particles in the free troposphere over Japan, Atmos. Res., 82, 698-708, 2006.

Köllensperger, G., Friedbacher, G., Grasserbauer, M., and Dorffner, L.: Investigation of aerosol particles by atomic force microscopy, Fresenius J. Anal. Chem., 358, 268-273, 1997.

Köllensperger, G., Friedbacher, G., Grasserbauer, M., and Dorffner, L.: In-situ investigation of aerosol particles by atomic force microscopy, Fresenius J. Anal. Chem., 361, 716-721, 1998.

Köllensperger, G., Friedbacher, G., Kotzick, R., Niessner, R., and Grasserbauer, M.: In-situ atomic force microscopy investigation of aerosols exposed to different humidities, Fresenius J. Anal. Chem., 364, 296-304, 1999.

Kühle, A., Sørensen, A. H., and Bohr, J.: Role of attractive forces in tapping tip force microscopy, J. Appl. Phys., 81, 6562-6569, 1997.

Lehmpuhl, D. W., Ramirez-Aguilar, K. A., Michel, A. E., Rowlen, K. L., and Birks, J. W.: Physical and chemical characterization of atmospheric aerosols by atomic force microscopy, Anal. Chem., 71, 379-383, 1999.

Levin, Z., Ganor, E., and Gladstein, V.: The effects of desert particles coated with sulfate on rain formation in the eastern Mediterranean, J. Appl. Meteorol., 35, 1511-1522, 1996.

Morita, S., Wiesendanger, R., and Meyers, E. (Eds.): Noncontact atomic force microscopy, Springer, Berlin, 439 pp., 2002.

Magonov, S. N., Elings, B., and Whangbo, M.-H.: Phase imaging and stiffness in tapping-mode atomic force microscopy, Surf. Sci., 375, L385-L391, 1997.

Martin, Y., Abraham, D. W., and Wickramasinghe, H. K.: Highresolution capacitance measurement and potentiometry by force microscopy, Appl. Phys. Lett., 52, 1103-1105, 1988.

Na, C., Kendall, T. A., and Martin, S. T.: Surface-potential heterogeneity of reacted calcite and rhodochrosite, Environ. Sci. Technol., 41, 6491-6497, 2007.

Nonnenmacher, M., O'Boyle, M. P., and Wickramasinghe, H. K.: Kelvin probe force microscopy, Appl. Phys. Lett., 58, 29212923, 1991.

Pósfai, M., Xu, H., Anderson, J. R., and Buseck, P. R.: Wet and dry sizes of atmospheric aerosol particles: An AFM-TEM study, Geophys. Res. Lett., 25, 1907-1910, 1998.

Ramirez-Aguilar, K. A., Lehmpuhl, D. W., Michel, A. E., Birks, J. W., and Rowlen, K. L.: Atomic force microscopy for the analysis of environmental particles, Ultramicroscopy, 77, 187-194, 1999.

Semeniuk, T. A., Wise, M. E., Martin, S. T., Russell, L. M., and Puseck, P. R.: Water uptake characteristics of individual atmospheric particles having coatings, Atmos. Environ., 41, 62256235, 2007.

Sokolov, I. Yu. and Henderson, G. S.: The height dependence of image contrast when imaging by non-contact AFM, Surf. Sci., 464, L745-L751, 2000.

Sokolov, I. Yu., Henderson, G. S., and Wicks, F. J.: Force spectroscopy in noncontact mode, Appl. Surf. Sci., 140, 358-361, 1999.

Takahashi, T. and Kawamukai, T.: Phase detection of electrostatic force by AFM with a conductive tip, Ultramicroscopy, 82, 6368, 2000.

Trochkine, D., Iwasaka, Y., Matsuki, A., Yamada, M., Kim, Y.S., Nagatani, T., Zhang, D., Shi, G.-Y., and Shen, Z.: Mineral aerosol particles collected in Dunhuang, China, and their comparison with chemically modified particles collected over Japan, J. Geophys. Res., 108, 8642, doi:10.1029/2003JD003268, 2003.

Villarubia, J. S.: Morphological estimation of tip geometry for scanned probe microscopy, Surf. Sci., 321, 287-300, 1994.

Viswanathan, R., Tian, J., and Marr, D. W. M.: Morphology characterization in multicomponent macromolecular systems using scanning probe phase microscopy, Langmuir, 13, 1840-1843, 1997.

Wittmaack, K. and Strigl, M.: Novel approach to identifying supersaturated metastable ambient aerosol particles, Environ. Sci. Technol., 39, 8177-8184, 2005.

Winterholler, B., Hoppe, P., Andreae, M. O., and Foley, S.: Measurement of sulfur isotope ratios in micrometer-sized samples by NanoSIMS, Appl. Surf. Sci., 252, 7128-7131, 2006. 